\title{
Adaptive kinematic textile architecture
}

\author{
Maria Wyller $^{1}\left[\right.$ Maria Yablonina ${ }^{1} \cdot$ Martin Alvarez $^{1} \cdot$ Achim Menges $^{1}[$
}

Received: 24 May 2020 / Accepted: 29 October 2020 / Published online: 30 November 2020

(c) The Author(s) 2020

\begin{abstract}
The research presented in this paper explores how textiles can be formed into adaptive, kinematic spaces to be able to respond to its environment and users utilizing on-site, distributed, mobile robotic connectors. The project aimed at creating an adaptive system that consumes little energy while making use of textiles' advantageous qualities—their lightweight, portability, and manipulability. This was achieved through the development of a bespoke on-material mobile machine able to locomote on suspended sheets of fabrics while shaping them. Together, the connector and the tectonic system compose a lightweight architectural robot controlled with a feedback loop that evaluates real-time environmental sensor data from the space against user-defined targets. This research demonstrates how the combination of mobile robotics and textile architecture opens up new design possibilities for adaptive spaces by proposing a system that is able to generate a significant architectural effect with minimal mechanical actuation.
\end{abstract}

Keywords Architectural robotics $\cdot$ Mobile robots $\cdot$ Adaptive architecture $\cdot$ Textile architecture $\cdot$ Kinematic architecture

\section{Introduction}

Adaptive architecture reacts to its environment, its inhabitants, or objects contained within it (Schnädelbach 2010). A common motivation for designing adaptive structures is to save resources. However, many systems fall in the paradox of using a lot of it, both through production and maintenance. Adaptive architecture often relies on numerous actuators, expensive computing, and continuous power supply to operate, usually due to the structural load applied to the mechanical elements.

The presented research aims to form textiles into adaptive, kinematic spaces able to respond to its environment using distributed, on-site, on-material, mobile robotic connectors. Together, the material and the connectors comprise a lightweight, energy-efficient system capable of producing a significant architectural change with minimal mechanical actuation. This research hopes to contribute to

Electronic supplementary material The online version of this article (https://doi.org/10.1007/s41693-020-00046-5) contains supplementary material, which is available to authorized users.

Maria Wyller

mariawyller@gmail.com

1 Institute of Computational Design, University of Stuttgart, Stuttgart, Germany the search for adaptive systems that consume less while providing a great spatial impact (Fig. 1).

A common objective of adaptive systems is to alter spatial parameters such as light, acoustics, temperature, and space division (Schnädelbach 2010). Textile's inherent material qualities allow them to influence all these factors just by being present (Bendixen 2010; Quinn 2006). They are wellsuited for adaptation because they can have a significant reversible impact on space through quick manipulation. Textiles can act as partitions, ceilings, covers, volumes, and thus produce a variety of architectural effects. By augmenting a textile element with a mobile robot, one can further leverage the results that these materials can offer towards scenarios where they can alter geometric and ambient characteristics of architectural space through continuous kinematic behaviors.

To keep the technology to material ratio at a minimum, the material relocation is conducted by a lightweight, twopart mobile robotic textile joint-the connector (Fig. 2). It is considered an extension of the textile itself, there to augment already innate material qualities. The control code produces and evaluates real-time environmental sensor data against preset, user-defined goals, and from this produces motor values that trigger the connector to move until the textile has taken on a configuration where the target is reached. The combination of the precise, computerized control of 
the connectors and the unpredictability of the textile's folding allows the system to respond to user-defined goals with unique configurations.

Whereas adaptive architecture often is approached through the development of project and location-specific adaptive building components, this research proposes an inherently flexible system, ready to be attached or detached, and with this make any static space, new or old, small or large, adaptive.

\section{Background}

Before humans settled as farmers, they all lived as nomads in adaptive structures and in this sense, adaptive architecture has been part of history longer than static environments (Jäger et al. 2016) However, it was not until the invention of the computer, which facilitated the integration of Information and Communication Technologies (ICT) in built environments, that the idea of adaptive structures able to sense, plan and act—or robotic buildings—came along (Gross and Green 2012).

Robotic Building can be defined as buildings relying “... on interactions between human and non-human agents not only at design and production level but also at building operation level, wherein users and environmental conditions contribute to the emergence of multiple architectural configurations" (Bier 2018). Some of the first descriptions of this were formulated by the avant-garde group Archigram. Their designs of "unbuilt utopias" “... destabilized the fundamental assumption that architecture is a static art:". They were unconvinced that a building's firmitas (solidity) was the necessary precondition of its utilitas and venustas (utility and beauty) (Sadler 2005). Many of Archigram's theories were subsequently furthered by the MIT Professor Nicholas Negroponte, who envisioned "a man-made environment that responds to and is "meaningful" for him or her" (Negroponte 1975).

Fig. 1 Full-scale demonstrator

Fig. 2 The connector

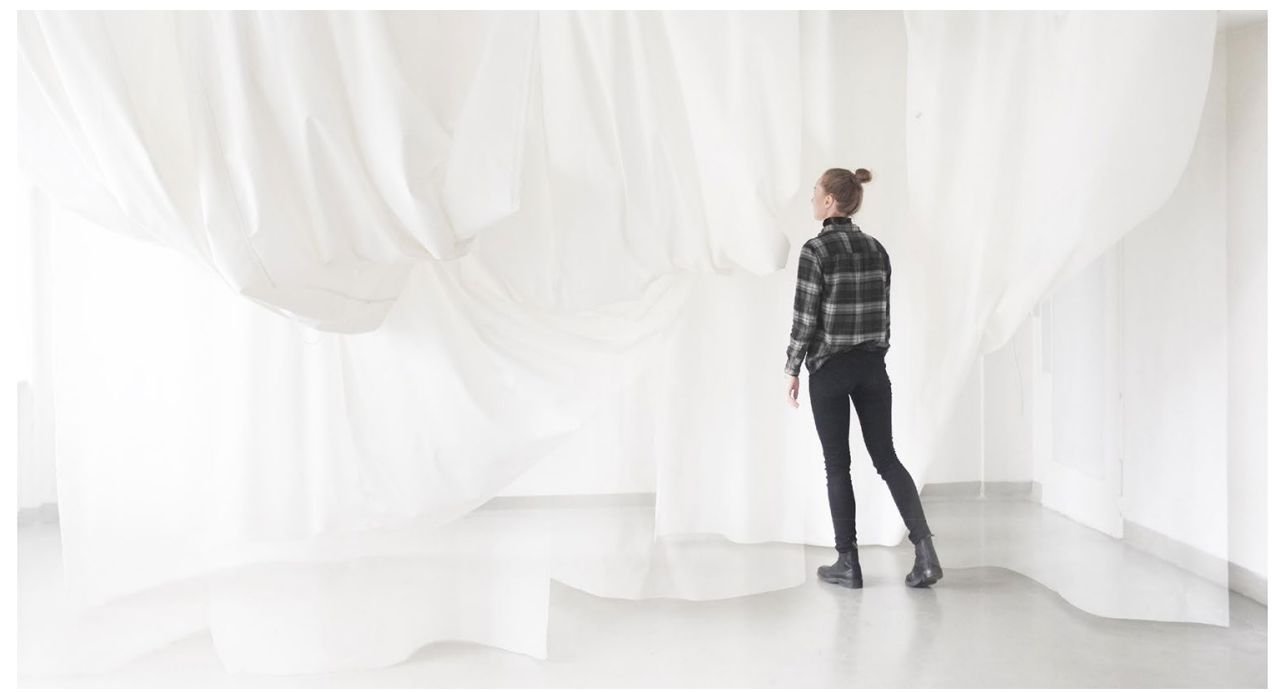


The concept of architectural robots has proved a challenge to realize as built projects. Jean Nouvel's Institut Monde Arab (1980), an early example of an adaptive envelope, experienced a frequent system failure due to a large number of exposed mechanical elements (Barozzi et al. 2016). Furthermore, both Axel Kilian's installation The Flexing Room (Kilian 2018), and the 2018/2019 ICD/ ITKE Research Demonstrator (ITECH Research Demonstrator 2018-19|Institute for Computational Design and Construction 2019) successfully interact with their inhabitants, but produce a relatively small geometry displacement, possibly because the adaptation of the structures requires the alternation between structural and flexible states.

However, some projects demonstrate how a diverse, kinematic behavior can be produced with a soft system and few actuators. The Hyperbody Research Group developed the project the MUSCLE, a programmable, pneumatic structure able to change its shape in real-time as a response to the changing activity level of users nearby (Oosterhuis 2004). In a Self-Choreographing Network (Fig. 3) the material behavior of bending active rods is activated by small machines and monitored with a realtime digital twin simulation (Maierhofer et al. 2019). In Choreographed Spaces (Fig. 3) mobile robots relocate sheets of textiles creating perceived spatial boundaries (Yablonina et al. 2019). All three projects utilize materials that are inclined to move, which significantly reduces the amount of hardware necessary to power the movement. This project intends to employ the same strategy by combining a small robotic actuator and a flexible material that allows for the propagation of the robotic behavior.

In both Self-Choreographing Network and Choreographed Spaces bespoke, distributed mobile robotics were utilized for system-actuation. Collaborative machines have been a field of interest among roboticists and computer scientists since the early 1980s (Yablonina et al. 2019), and have experienced a resurgence over the past years due to faster, cheaper, and more accessible hard- and software (Tan and Zhong-yang 2013). Many projects exploring multi-agent systems and swarm robotics for construction purposes have been developed, ranging from aerial robots (Mirjan et al. 2014) to climbing robots (Petersen et al. 2012). Several projects find inspiration in various animal builders capable of erecting constructions many times the weight of each individual builder through effective collaboration (Petersen et al. 2012).

For the project presented in this paper a mobile, textile climbing robot was developed, able to climb on vertical surfaces while relocating textile elements many times its size and weight. Using a small, mobile actuator makes it possible to realize a flexible and scalable system: the connector can operate in spaces of various sizes, alone or in collaboration with other connectors, it can also be added or taken away depending on what robotic resolution the user wants the adaptive space to have.

\section{Methods}

In the presented research the aim is to create a physically built robotic environment consisting of textile aggregations reconfigured by mobile connectors in response to real-time sensor data and user-defined environmental goals. It explores how a small robotic unit can, with simple configurations, generate a considerable spatial effect. The human plays the role of both the inhabitant and the facilitator of the system.

\subsection{Overall system set-up}

The proposed set-up consists of an aggregation of vertically suspended textile elements manually attached to the ceiling by a human. Subsequently, these are shaped into
Fig. 3 Left: self-choreographing network (Maierhofer et al. 2019), right: choreographed spaces (Yablonina et al. 2019)

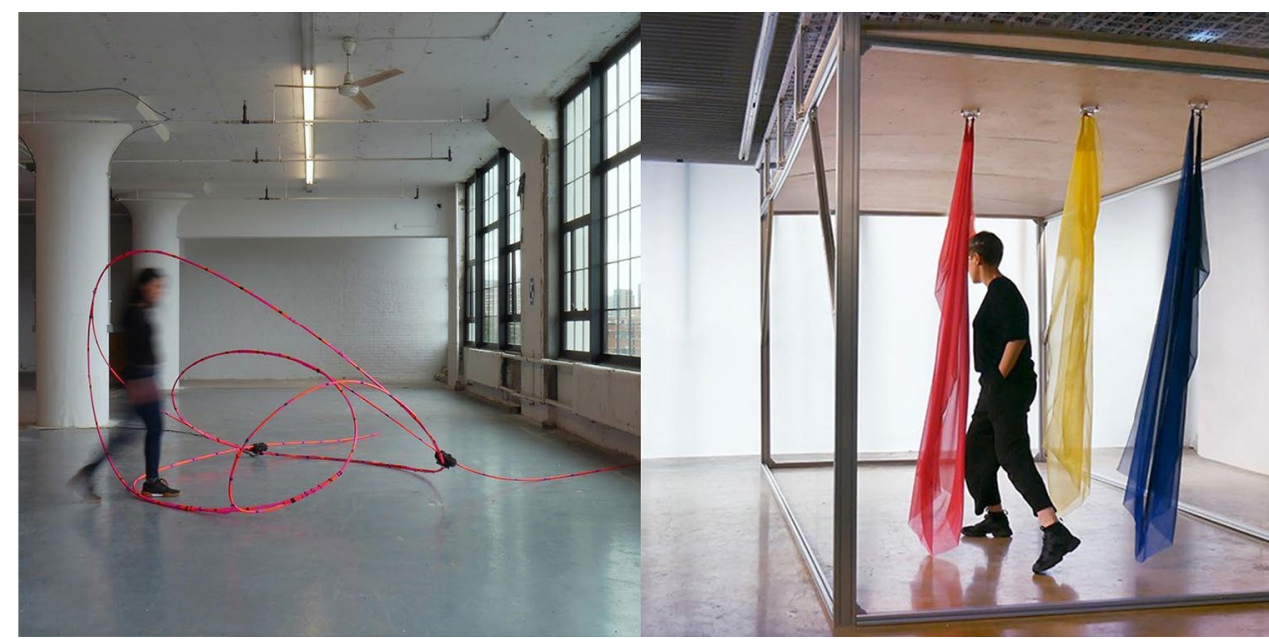


$3 \mathrm{~d}$-arrangements when joined together with a connector. The movement of the connector and the succeeding reconfiguration of the space is produced by a feedback loop, which evaluates the current state of the system derived from real-time sensor data provided by sensor units placed in the space, and predefined environmental targets set by the user. Based on the deviation between the desired state and the actual state of the system, it returns motor values for the connector, which moves and makes the textile reconfigure. When the target value is achieved, the connector either moves to maintain the current state or stops to await a new goal (Fig. 4).

\subsection{Tectonic system}

The potential of the adaptation is dependent on the initial placing of the textile elements and connectors. Each textile element defines the locomotion boundary of the connector and therefore also the space in which the reconfiguration can take place (Fig. 5). If the textile is attached linearly as a conventional partition to the ceiling, the area of operation for the connector and the following textile reconfiguration is limited to a two-dimensional plane. The diversity of the textile geometries is increased when the textile is attached in a curve because it allows for connector locomotion in three dimensions. The geometric results can be further diversified by layering the textile or creating cut-outs (Fig. 6).

Another defining factor for the potential of the reconfiguration is the initial placement of the connector. Four joints were evaluated for the project, B, $\mu, \mathrm{H}$, and Y (Fig. 5). The first three of these connections $\mathrm{B}, \mu$, and $\mathrm{H}$ produced the most three-dimensional reconfigurations and were concluded the most promising for geometric change.

\subsubsection{Textiles' influence on environmental variables}

The material's ability to diffuse and reflect light relies on the distance between the light source and the textile element. If the sheet is placed perpendicular to the light source, space is modulated not only with the material but also with light. Consequently, by animating the textile, the diffusion, absorption, and reflection of light are also animated (Fig. 7).

Furthermore, textiles can significantly influence the acoustics of a space, and by reconfiguring the textile, exposing and covering reflective surfaces, going from a flat state to a voluminous state, the reverberation time of a space can be altered. The thickness of the material, position relative to reflective surfaces, and amount of draping influence the potential impact. (Bendixen 2013).

\subsubsection{Materiality}

For the full-scale experiments conducted in the project, three types of fabrics were used: cotton, linen, and nylon. For the final demonstrator nylon was employed because linen was too heavy to be carried high by the connector, and cotton produced less interesting two-dimensional drapings.

Fig. 4 System overview

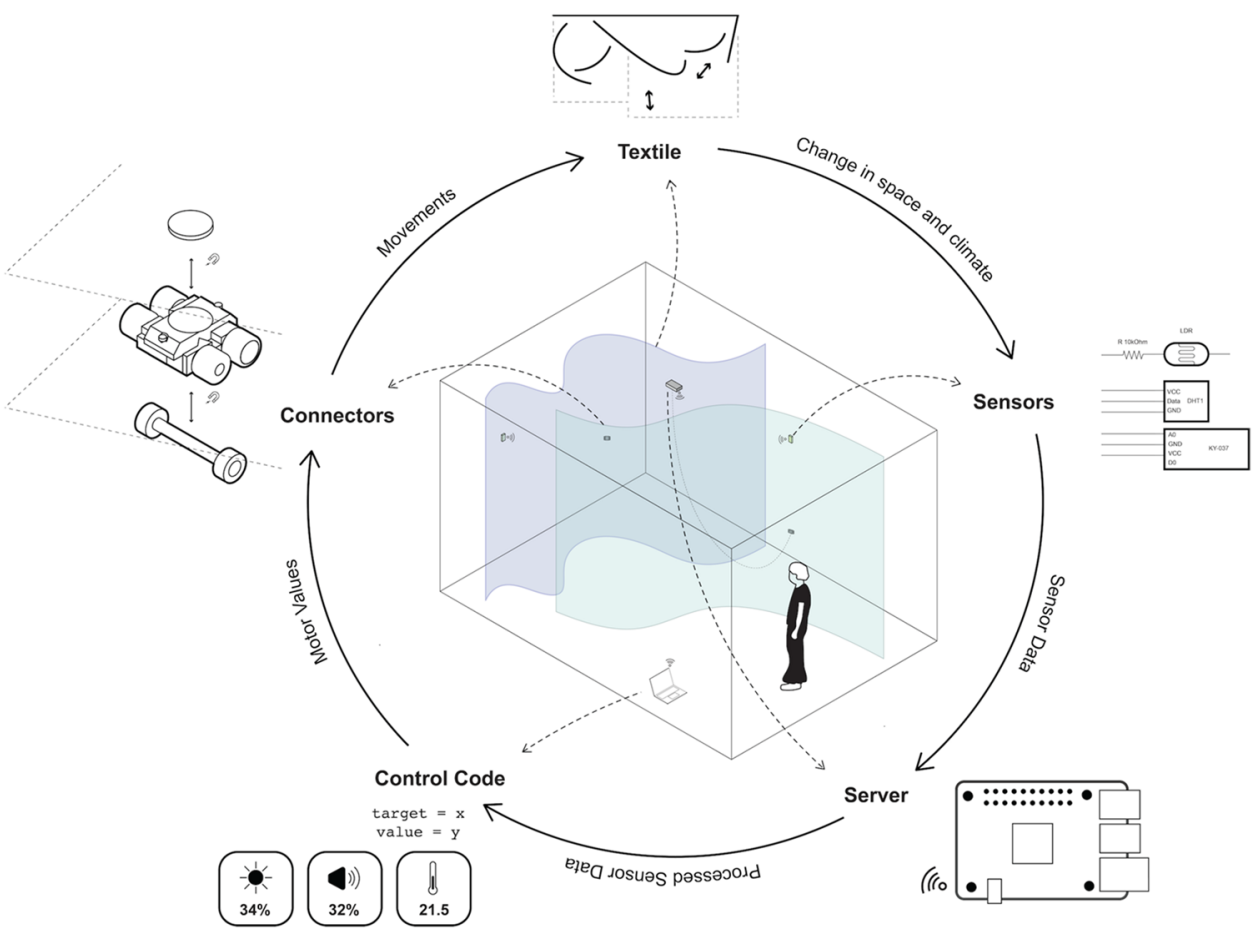




\subsection{Connector development}

\subsubsection{Hardware design}

Several robots capable of climbing on textiles serves as references for the connector, ranging from the interactive wearable Rovables (Dementyev et al. 2016) to the ultra-light-weight CLASH (Birkmeyer et al. 2011). However, neither of them are designed to carry a large load beyond their own weight, therefore, it was important to combine the lightweight of these robots with the robustness of larger vertical climber such as The Sheet Climber (Yablonina and Menges 2019) (Fig. 8).

The connector consists of two 3D-printed parts, active and passive, held together with neodymium magnets embedded in the wheels (Fig. 9). The active body holds a pair of DC micro gear motors with a relatively high gear ratio. Initially, the parts were combined with a large alignment magnet centrally positioned on the connector body as in The Sheet Climber (Yablonina and Menges

Fig. 5 Library of textile connections and respective robot configurations

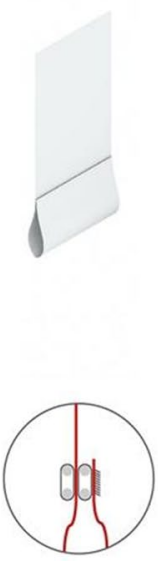

b
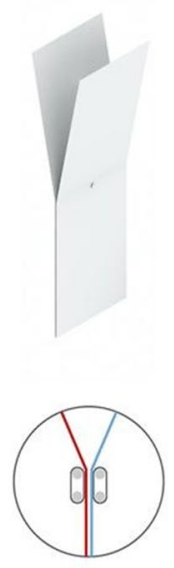

$Y$
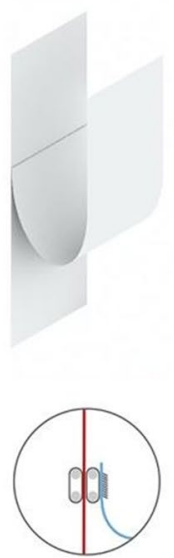
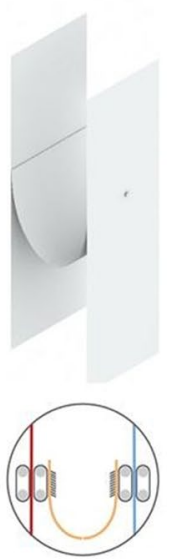

H

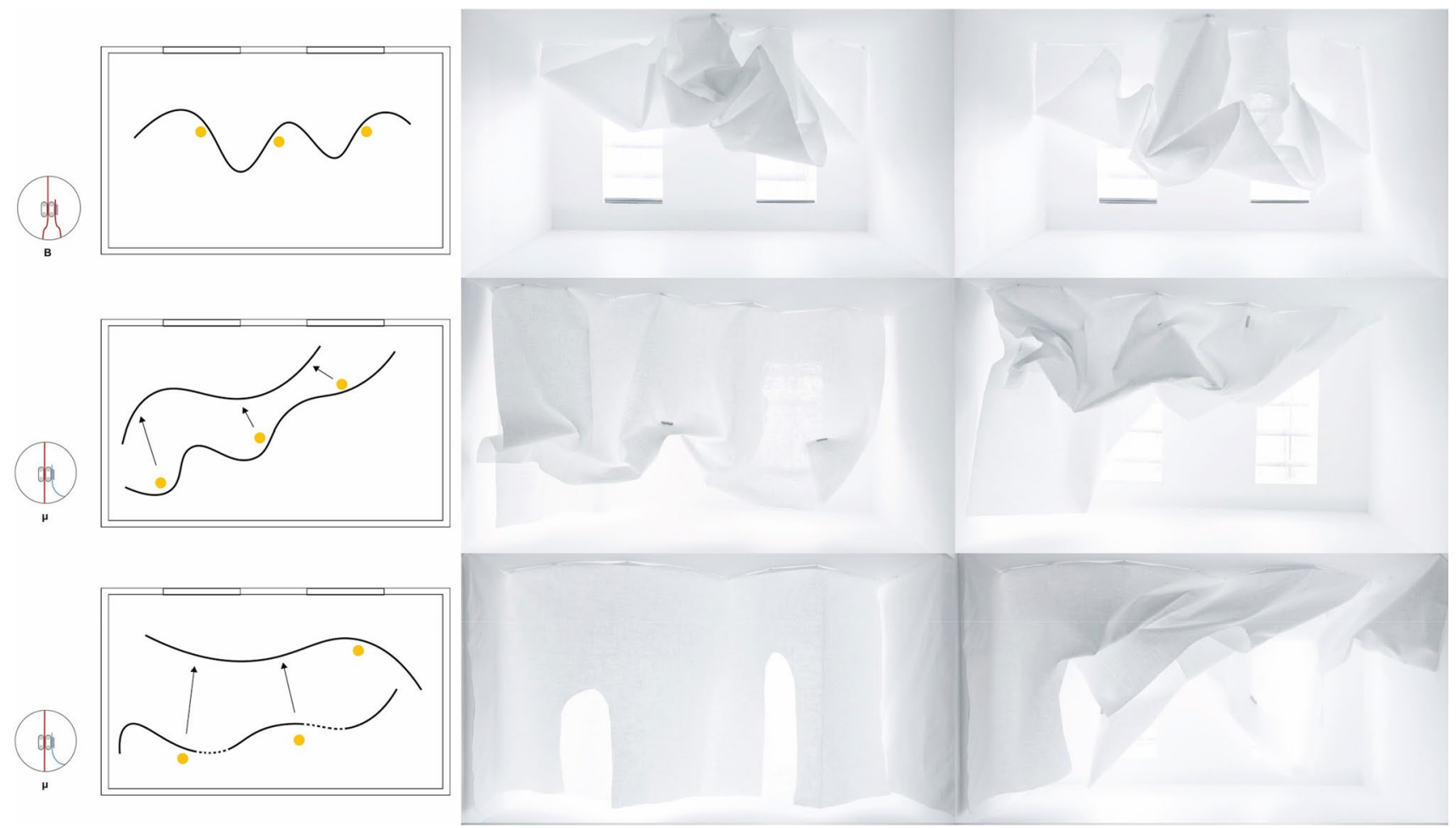

Fig. 6 From the top: a curved ceiling attachment, b layering, $\mathbf{c}$ cut-outs. Model 1:10. Magnets were manually moved to simulate the connector movement 
2019). However, the size of the machine was considerably reduced by employing the same strategy as in Rovables (Dementyev et al. 2016) and including ring magnets in the wheels. A large magnet was placed on the back of the active body, offering a fast and flexible option for attaching the textile.

Each connector used a differential drive programmed in Python controlled over a Waveshare Motor Driver HAT and a Raspberry Pi $3 \mathrm{~b}+$. The Waveshare driver offered an i2C interface with up to 16 addresses, which meant that up to 16 connectors could be controlled simultaneously from one Raspberry Pi.

In total, each connector weighed $80 \mathrm{~g}$, cost $\approx 25$ euro to produce, needed 1 amp to operate, and could carry about 4 square meters of material $(2-3 \mathrm{~kg})$. It primarily consumed energy when moving. Each connector could be attached in parallel and form a stronger machine. Tethered connectors were used in all experiments shown in this paper. Nonetheless, it could easily be made tetherless with, for example, a Wemos D1 mini-board, a TB6612FNG driver, and a lightweight, rechargeable $5 \mathrm{~V}$ battery. It would be advisable to customize the board with all drivers and sensors embedded to reduce its size.

\subsubsection{Control and localization}

System control, whether autonomous or manual, is imperative for a successful operation of mobile robotic systems. While an autonomous operation is preferred for systems with multiple collaborating agents, a manual mode is useful for troubleshooting and system exploration. Robot localization can prevent collisions and navigation outside of the environment, however, because of the variety of set-ups in which mobile robots are employed, it is difficult to generate a universal method. Some of the elegance of a minimal robot is lost when large and expensive external hardware such as cameras or trackers are required for a successful operation.

Two modes of operations were explored for the proposed system: a manual mode that permitted the user to control the connector movements at any time during execution, and an autonomous mode where the connector movement was entirely controlled based on the user-set goals and the feedback from the environmental sensors. In the autonomous mode, the connector's path could be continually corrected with an inertial measurement unit (IMU). From the readings, the current angle of the connector relative to the initial calibration was measured. If it deviated from the intentional, the connector corrected its position by rotating before it continued in the planned direction (Fig. 10).
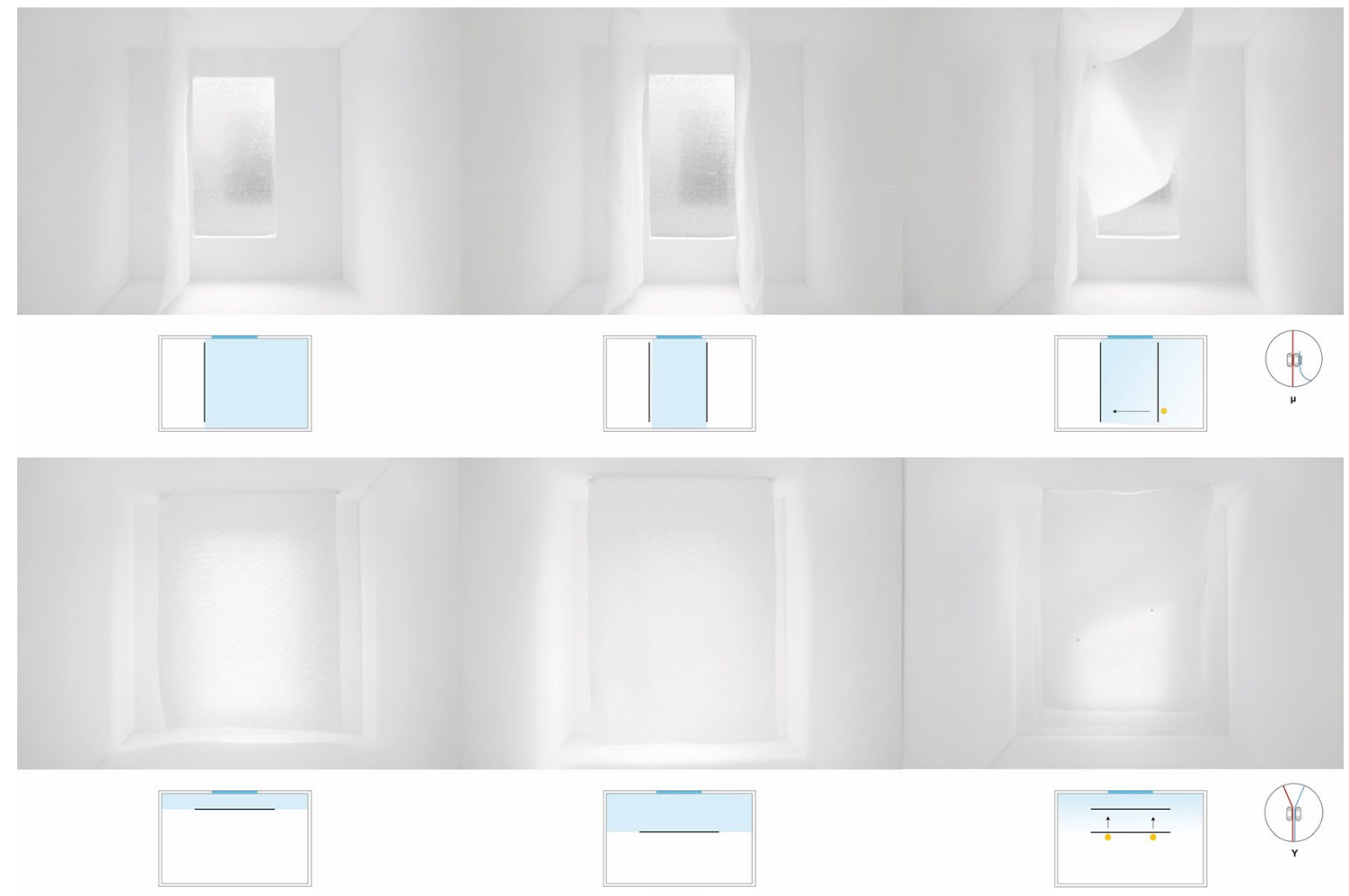

Fig. 7 Light studies. The blue area shows which areas receive direct light. Model 1:10 


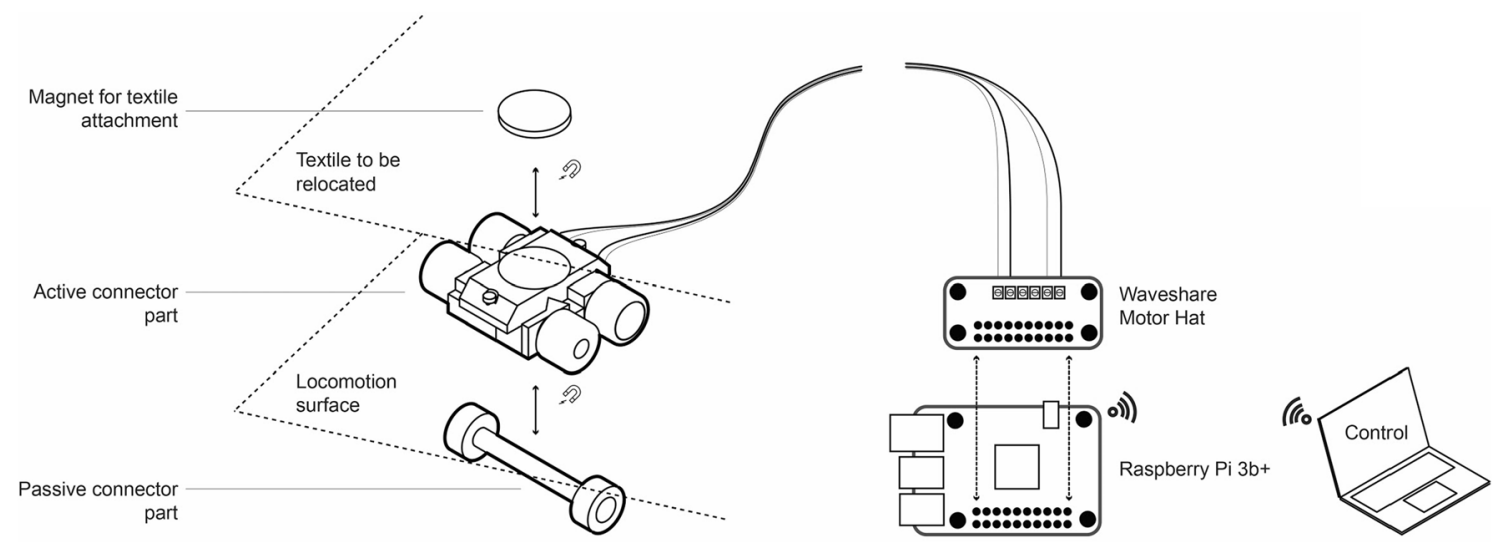

Fig. 8 Connector hardware and set-up

Fig. 9 Exploded diagram of the connector design

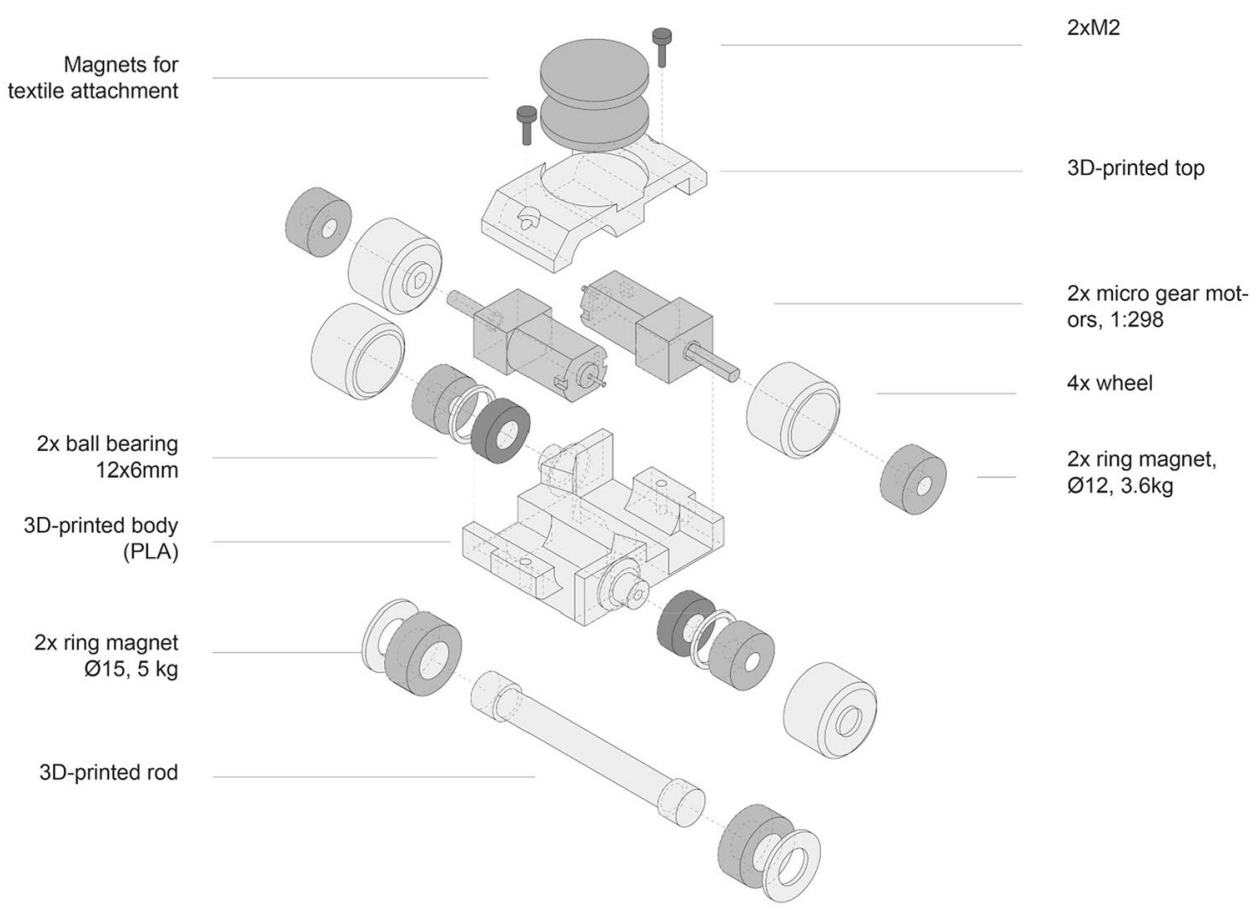

For this project, conventional tracking systems such as computer vision-based tracking, IR-tracking, or radio signals were evaluated but excluded because the textile aggregates would interfere with the communication between the sender and the receiver. The same problem had to be addressed in Choreographed Spaces, and the solution was to cover the robot's locomotion surface with fiducial markers read by the robots with a camera (Yablonina et al. 2019). A similar approach was tested in this project (Fig. 11). The connector read the rhythm of on-drawn lines with an IR-sensor to track its position and progression ( 1 line $=+-1 y$-unit, 2 lines $=+-1 x$-unit, 3 lines $=$ edge of textile). This method influenced the appearance of the material, but with more development, the lines could be further embedded in the design of the textile and thus provide an integrated, powerand computing effective localization method for on-material robots.

\subsection{Sensor set-up and system control}

The autonomous, or sensor-driven, operation mode was based on the environmental sensor readings and predefined user goals. Sensor pods-small, 3D-printed containers holding a half-size breadboard and sensors were placed at various locations at eye-level in the space. The system was calibrated by identifying the maximum and minimum sensor values possible to achieve in the space at that time. 


\subsubsection{Feedback loop}

To connect the different components of the system: the textile aggregations, the connectors, the environmental sensors, and the user, a framework for a Design-To-Robotic-Production and Operation feedback loop, a mode of production and operation where both human and non-human agents are involved (Bier et al. 2018). The code was composed of custom classes and methods written in Python. The main code was executed with thread-based parallelism to ensure a robust system able to handle multiple processes at the same time. With this, the control code could receive and evaluate multiple streams of sensor data with perceived concurrency (i.e. sensor readings from multiple environmental sensors, IR-readings for the connector localization, IMU-readings for path correction, and joystick values for manual control). Based on the deviation between the target values and the measured values, the direction and the speed of the connector was returned as motor values.
The direction of the robot was determined from a small library of connector methods based on the empirical conclusions drawn from the full-scale textile experiments. For example, if the current light value was measured to be lower than the target value, the function producing a forwards (upwards) movement would be prompted, because it was concluded from the textile experiments that relocating the textile upwards would make the space lighter (Fig. 12).

The speed of the robot was dependent on the deviation of the current value and the target value. The larger the difference (measured relatively) between the two values, the larger the speed. A next step would be to implement an attractorbased function in which the speed of the connector would be a product of both the sensor-target value divergence and the connector's physical distance to the sensor dock. This would ensure that only the connectors with a relevant influence on a sensor dock would move.
Fig. 10 Overview of the restraints of the connector
Fig. 11 Localization. Left: physical position of connector, right: digital representation
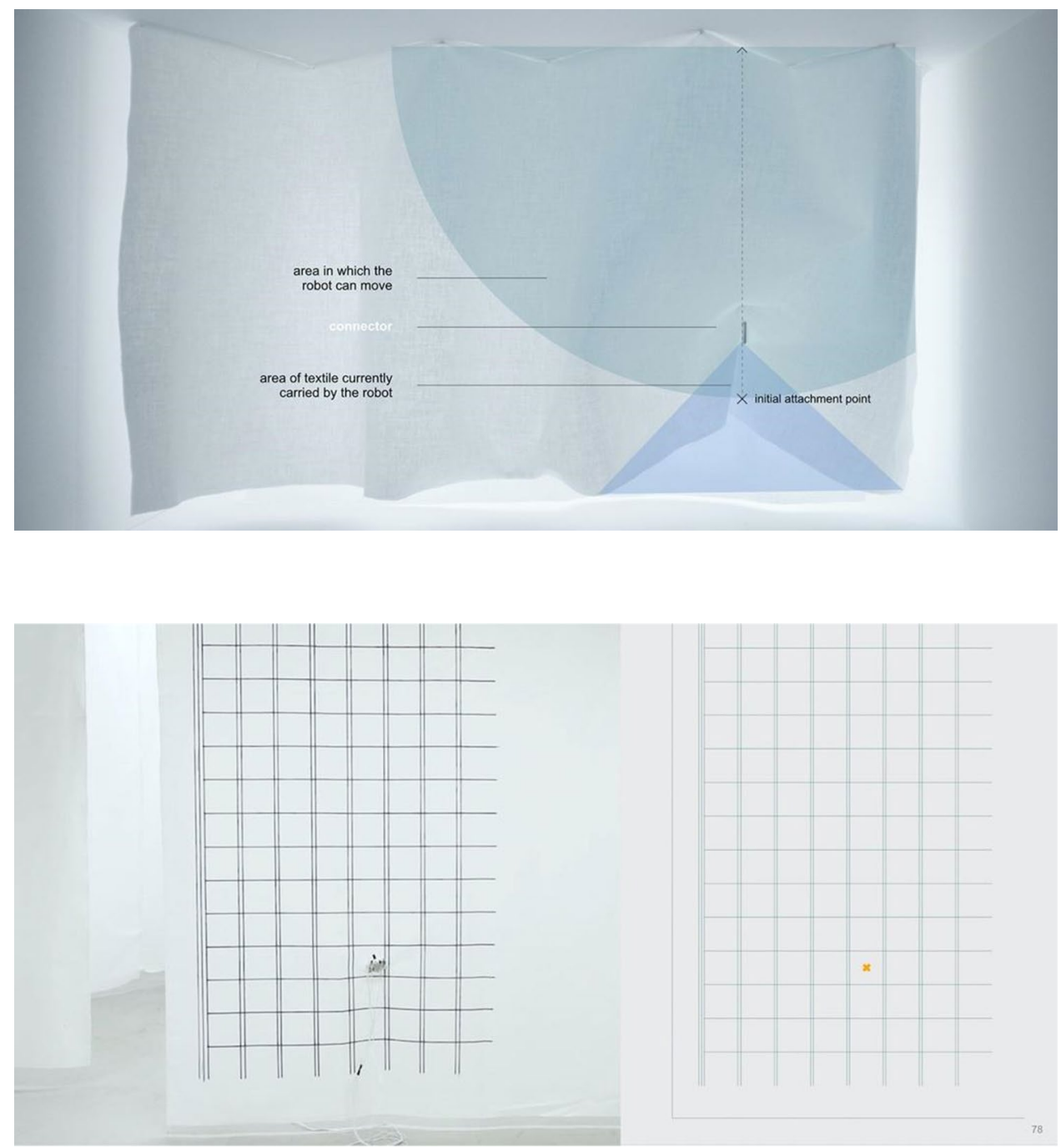


\subsection{Full-scale demonstrator}

A series of experiments were conducted in a full-scale demonstrator consisting of 35 sqm of textile (nylon) and 4-8 connectors.

\subsubsection{Geometric impact}

The interplay of multiple connectors created an imposing geometric effect when their relative directions, rhythms, and speeds were altered. By moving all connectors in the same direction with the same speed and rhythm, the textile was perceived as one moving body actuated by a single actuator. By differing the rhythm or direction of the connectors, the individual presence if each was expressed spatially creating an almost fluid motion.

The geometry of the connector path significantly influenced the final textile configuration. The result of a linear motion (Fig. 13, left) substantially differed from a curved (Fig. 13, right). The sequence and direction in which the connector collected the textile had a notable impact on the resulting geometry. This effect could only be achieved with the proposed on-material mobile robot because it could collect the textile non-linearly.

\subsubsection{Sensor experiments}

A smaller demonstrator of three sheets of textile and 2 connectors was set-up for validating the proposed control system and its overall ability to adapt to various scenarios. Whereas only light-dependent resistors (LDR) were used in the experiments, several LDRs were placed in the same sensor dock to prove the capability of the control set-up to handle multiple streams of sensor data and to achieve accurate readings. The user fed the controller with various targets, which the connector successfully achieved.

\section{Results and reflection}

The experiments presented in this paper verify the geometric potential of a responsive, architectural system of textile aggregations reconfigured by mobile robotic connectors insitu, and demonstrate the potential of the system's ability to regulate architectural and environmental parameters.

The bespoke, power-, material-, and cost-effective mobile connector, able to locomote on a textile surface while relocating either a neighboring textile element or the locomotion surface itself, shows how a small machine can produce a significant spatial change when coupled with the right material. The connector successfully carried a load 25 times its own weight, and produced impressive geometric results especially when it collaborated with other connectors. Furthermore, it proved a competent textile climber, and could be further developed to perform fabrication tasks on textiles such as embroidery or stitching.

A feature of the proposed on-material robot actuation system is that the user has the freedom to actively participate in the adaptation of the space by changing an important premise of it: the initial connector position. However, this freedom also leads to possible conflicts and a less predictable control of the system. The user can place all connectors in one part of the room, but require another part of the room in which the connectors cannot move to change. An important next step in the development of the feedback loop is to enable feedback not only to the machines but also to the user.

Textile production is in itself a very algorithmic process (Devendorf 2019), and this could be explored by, for example, weaving information readable by the robots directly into the textiles. This may be embedded sensors, textures, colors, patterns, and shapes. The visual appearance of the textile would be a product of the computational processes and robotic constraints that enable the control of their adaptivity.

Fig. 12 Control loop overview

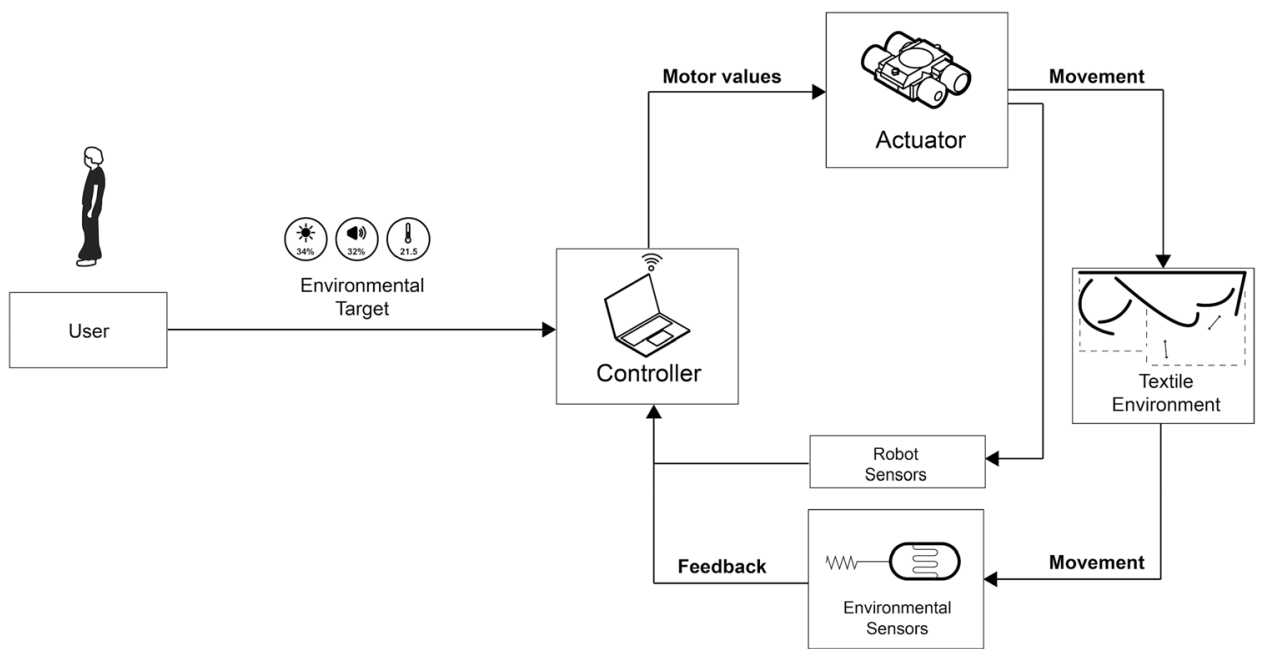


Fig. 13 Left: I movement, right, J movement

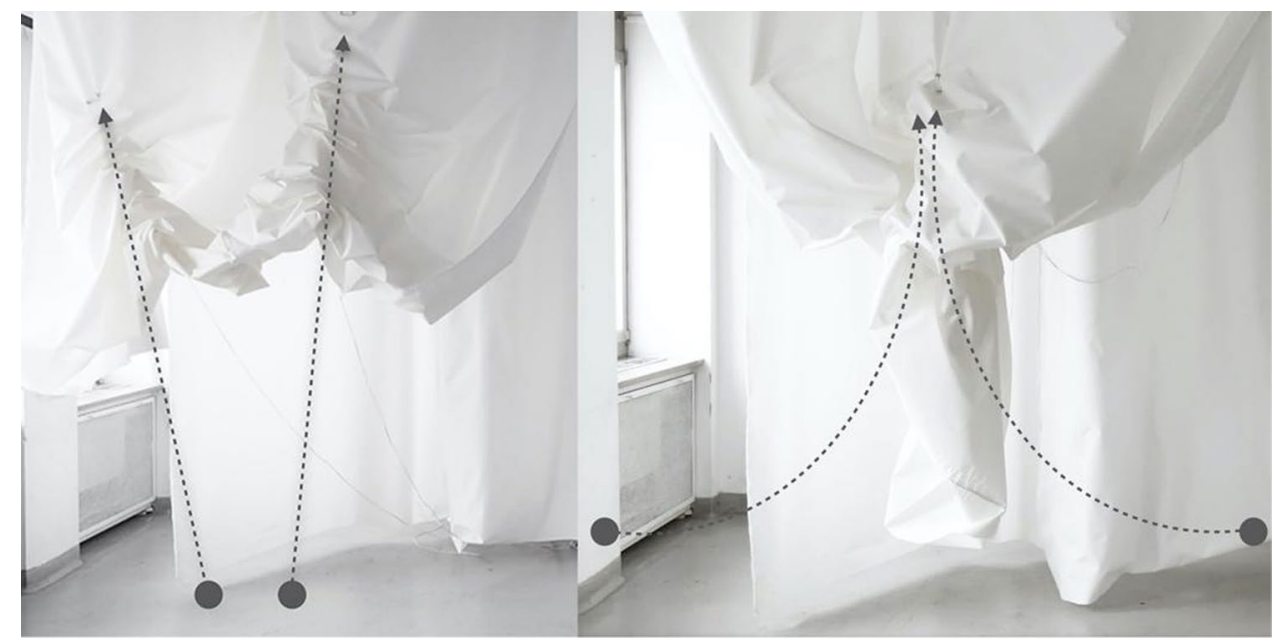

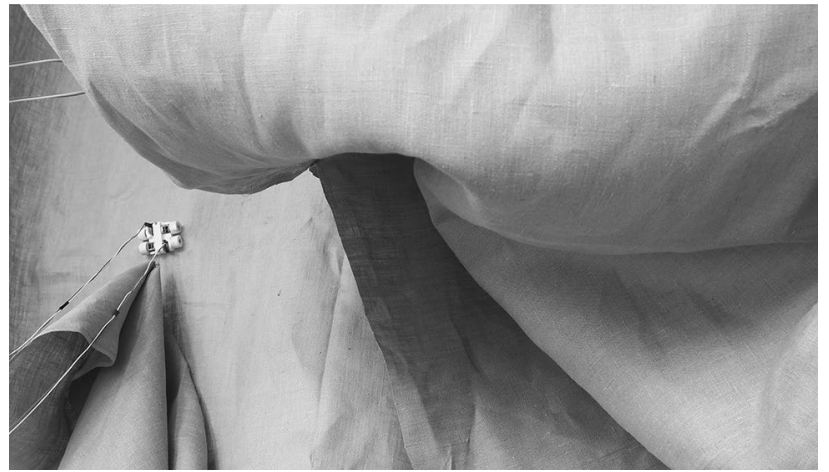

Fig. 14 Detail, full-scale demonstrator

\section{Outlook}

Textiles were for millennia largely excluded from architectural theory and practice (Garcia 2006). As a flexible material often associated with the fragile, ephemeral, feminine, tacit, and manipulable, it was given little space in a tradition that valued the powerful, the constant and where the Vitruvian concept of firmitas (solidity) still dictated what could be functional (utilitas) and beautiful (venustas) (Garcia 2006) (Fig. 14).

In the past years, textiles have found a place in the architectural debate through research on fiber-composite building systems. The focus is, however, primarily on textile's considerable strength, not on its inherent flexibility. In an ever more shifting political and environmental world, adaptability, flexibility, and portability are more relevant than ever. UKGBC writes that: "Newly constructed buildings are more energy efficient, but $80 \%$ of buildings in 2050 have already been built, so a major priority is decarbonising our existing stock" (UKGBC). An important task of the architect of the future may be to develop robust, lightweight, adaptive systems capable of transforming existing spaces. Textiles, with its inherent ability to influence the environment paired with mobile machines, might provide a cheap, efficient, and lightweight alternative.

This project wishes to embrace the material's dramaturgy, its ability to veil and unveil, to illuminate, to sharpen and to diffuse light and contribute to the field of adaptive textiles architecture with a soft, light, and intelligent robotic system.

Acknowledgements Achim Menges acknowledges the support by the Deutsche Forschungsgemeinschaft (DFG, German Research Foundation) under Germany's Excellence Strategy-EXC 2120/1-390831618. The authors are grateful for Rebeca Duque Estrada valuable contributions to the project and the useful feedback on the paper.

Funding Open Access funding enabled and organized by Projekt DEAL. This study was funded by Deutsche Forschungsgemeinschaft (Grant no. EXC 2120/1-390831618).

Availability of data and material Data sharing not applicable to this article as no datasets were generated or analyzed during the current study.

\section{Compliance with ethical standards}

Conflict of interest On behalf of all authors, the corresponding author states that there is no conflict of interest.

Code availability The codes written during the current study are available from the corresponding author on reasonable request.

Open Access This article is licensed under a Creative Commons Attribution 4.0 International License, which permits use, sharing, adaptation, distribution and reproduction in any medium or format, as long as you give appropriate credit to the original author(s) and the source, provide a link to the Creative Commons licence, and indicate if changes were made. The images or other third party material in this article are included in the article's Creative Commons licence, unless indicated otherwise in a credit line to the material. If material is not included in 
the article's Creative Commons licence and your intended use is not permitted by statutory regulation or exceeds the permitted use, you will need to obtain permission directly from the copyright holder. To view a copy of this licence, visit http://creativecommons.org/licenses/by/4.0/.

\section{References}

Barozzi M, Lienhard J, Zanelli A, Monticelli C (2016) The sustainability of adaptive envelopes: developments of kinetic architecture. Procedia Eng. https://doi.org/10.1016/j.proeng.2016.08.029

Bendixen C (2010) The textile form of sound. Duck J Res Text Text Des $1(1): 13$

Bendixen C (2013) Så vidt et rum: en undersøgelse af hvordan tekstil kan/ skal formgives og placeres for samtidigt at absorbere lyd og danne rum. Kunstakademiets Designskole

Bier H (2018) Preface. In: Bier H (ed) Robotic building. Series in adaptive environments. Springer, Berlin, p. vii-viii

Bier H, Cheng AL, Mostafavi S, Anton A, Bodea S (2018) Robotic building as integration of design-to-robotic-production and operation. Springer series in adaptive environments. https://doi. org/10.1007/978-3-319-70866-9_5

Birkmeyer P, Gillies AG, Fearing RS (2011) CLASH: Climbing vertical loose cloth. In: 2011 IEEE/RSJ International Conference on Intelligent Robots and Systems, San Francisco, CA, pp. 5087-5093. https ://doi.org/10.1109/IROS.2011.6094905

Climate change UKGBC's vision for a sustainable built environment is one that mitigates and adapts to climate change. (n.d.). Retrieved 26. November, 2020. from https://www.ukgbc.org/climate-change/

Dementyev A, Kao H-L, Choi I, Ajilo D, Xu M, Paradiso JA, Schmandt C, Follmer S (2016) Rovables. In: Proceedings of the 29th annual symposium on user interface software and technology-UIST ' 16. ACM. https://doi.org/10.1145/2984511.2984531

Devendorf L (2019) 19 Fabricating (smart) textiles-computational design, craft, and radical possibility (SCF2019, San Francisco, United States of America). https://www.youtube.com/watch ?v=RsWuZD61I6E\&fbclid=IwAR2SAP3A1-1ZxoRiBNPr2Q3kc QDh-NsciWi3eCAjGhXhhtEnVIEdFdSJbc0. Accessed 19 Aug 2019

Garcia M (2006) Prologue for a history and theory of architextiles. Archit Design 76:12-20. https://doi.org/10.1002/ad.346

Gross MD, Green KE (2012) Architectural robotics, inevitably. Interactions. https://doi.org/10.1145/2065327.2065335

ITECH Research Demonstrator 2018-19|Institute for Computational Design and Construction (2019) Institute of Computational Design University of Stuttgart. July 2019. Retrieved November 26, 2020 from. https://icd.uni-stuttgart.de/?p=27390

Jäger N, Schnädelbach H, Hale J (2016) Embodied interactions with adaptive architecture. Hum Comput Interact Ser. https://doi. org/10.1007/978-3-319-30028-3_9

Kilian A (2018) The Flexing Room Architectural Robot." Acadia 2018 Recalibration on imprecision and infidelity. Universidad Iberoamericana I Mexico City 2018
Maierhofer M, Soana V, Yablonina M, Suzuki S, Koerner A, Knippers J, Menges A (2019) Self-choreographing network: towards cyberphysical design and operation processes of adaptive and interactive bending-active systems, in ACADIA - Ubiquity and Autonomy [Proceedings of the 39th ACADIA Conference 2019], The University of Texas at Austin, Austin, TX, pp. 654-663. (ISBN: 978-0-578-59179-7)

Mirjan A, Gramazio F, Kohler M (2014) Building with flying robots. In: Gramazio F, Kohler M, Langenberg S (eds) Fabricate: negotiating design \& making. UCL Press, London, pp 267-271

Negroponte N (1975) Soft architecture machines. MIT Press, Cambridge

Oosterhuis K (2004) File to factory and real time behavior in architecture, fabrication: examining the digital practice of architecture. In: Proceedings of conference of the AIA technology in architectural practice knowledge community, Cambridge/Ontario

Petersen K, Nagpal R, Werfel J (2012) TERMES: an autonomous robotic system for three dimensional collective construction. In: DurrantWhyte H, Roy N, Abbeel P (eds) Robotics: science and systems VII. MIT Press, Cambridge, pp 177-184

Quinn B (2006) Textiles in architecture. Archit Des. https://doi. org/10.1002/ad.348

Sadler S (2005) Archigram: architecture without architecture. The MIT Press, Cambridge

Schnädelbach H (2010) Adaptive Architecture - A Conceptual Framework. In: Geelhaar J, Eckardt F, Rudolf B, Zierold S, Markert M, (Eds.) proceedings of MediaCity: Interaction of Architecture, Media and Social Phenomena, Weimar, Germany, 2010, pp. 523-555

Schnädelbach H, Glover K, Irune AA (2010) ExoBuilding: breathing Life into architecture. In: Lárusdóttir MK, Hvannberg EP, Blandford A, Gulliksen J (Eds.) NordiCHI 2010: proceedings of the 6th Nordic Conference on Human-Computer Interaction, October 16-20, 2010, Reykjavik, IcelandACM Press. https://doi.org/10.1145/18689 14.1868965

Tan Y, Zhong-yang Z (2013) Research advance in swarm robotics. Def Technol 9(1):18-39

Yablonina M, Menges A (2019) Distributed fabrication: cooperative making with larger groups of smaller machines. Archit Des. https://doi. org/10.1002/ad.2413

Yablonina M, Leder S, Kalousdian NK, Menges A (2019) Choreographed Space: Distributed Mobile Robotic System for Temporal Architectural Change, in ICETAD [Proceedings of the ICETAD Conference 2019], Ryerson University, Toronto. (ISBN: 978-1-64713-769-4)

Publisher's Note Springer Nature remains neutral with regard to jurisdictional claims in published maps and institutional affiliations. 